\title{
Literature Review Analisis Ketidaklengkapan Rekam Medis Rawat Inap Di Rumah Sakit
}

\author{
Literature Review Analysis of Incomplete Medical Records In Hospital \\ Nevita Rahmawati ${ }^{1}$, Istiqlal Fithri ${ }^{2}$, Tegar Wahyu Yudha Pratama ${ }^{3}$ \\ ${ }^{1,2,3}$ Program Studi DIII Perekam Dan Informasi Kesehatan, Sekolah Tinggi Ilmu Kesehatan \\ (STIKES) Muhammadiyah Bojonegoro Jl. Ahmad Yani No.14 Kapas Bojonegoro \\ *e-mail korespondensi: nevitarahma@yahoo.com
}

\begin{abstract}
Abstrak
Latar Belakang : Analisis ketidaklengkapan pengisian rekam medis sangat diperlukan, guna mengetahui seberapa besar angka ketidaklengkapan pengisian catatan medis (AKLPCM) di RSU Mitra Medika pada tahun 2018. Ditemukan bahwa dari seluruh berkas rekam medis pasien pulang dari rumah sakit terdapat 13.279 berkas terdapat ketidaklengkapan pengisian sebanyak 7,66\% (1.017) berkas. Salah satu diantaranya adalah ketidaklengkapan pengisian resume medis, ketidaklengkapan pengisian identitas pasien sebanyak 5 formulir (16,6\%), anamnese 4 $(13,3 \%)$, pemeriksaan fisik $2(6,6 \%)$, diagnosa $1(6,6 \%)$, pemeriksaan penunjang $4(13,3 \%)$ dan tindakan medis sebanyak 2 formulir $(6,6 \%)$. Tujuan : Tujuan dari literature review ini adalah untuk untuk menganalisis Ketidaklengkapan Rekam Medis Rawat Inap Di Rumah Sakit. Metode: penelitian ini menggunakan desain literature review yaitu uraian tentang teori, bahan dan isi penelitian yang mengkaji tentang ketidaklengkapan rekam medis rawat inap di rumah sakit berdasarkan literature yang di review. Hasil : berdasarkan 8 jurnal di jelaskan bahwa Pengisian ketidaklengkapan rekam medis dari hasil penelitian menunjukan bahwa tidak lengkap masih tinggi pada angka $100 \%$ menandahkan kejadian ketidaklengkapan masih sering terjadi dan tidak sesuai dengan standart kelengkapan berkas rekam medis. Kesimpulan: Mengadakan monitoring evaluasi minimal 1 minggu sekali, membuat tim monitoring kelengkapan berkas untuk memantau pelaksanaan rekam medis di rumah sakit Kesimpulan : Mengadakan monitoring evaluasi minimal 1 minggu sekali, membuat tim monitoring kelengkapan berkas untuk memantau pelaksanaan rekam medis di rumah sakit
\end{abstract}

Kata Kunci : Ketidaklengkapan rekam medis, Rawat Inap, Langkah meningkatkan kelengkapan

\begin{abstract}
Background: incompleteness analysis of medical record-charging is essential, in order to see how high the incompleteness of medical records (aklpcm) in medika's partner-general general in 2018. It was found that from all the records of patients returning from the hospital there were 13,279 files of this incompleteness charging $7.66 \%$ $(1,017)$ of the files. One is the incompleteness of medical resumes, the incompleteness of the patient's 5 forms (166\%), anamnese 4 (13.3\%), physical 2 (6.6\%), diagnostic $1(6.6 \%), 4(13.3 \%)$ and 2 forms $(6.6 \%)$ medical action. Purpose: the purpose of this literature review is to analyze the incompleteness of hospital hospital medical records. Method: the study USES the design literature review, which is a description of theory, the material and content of the study that deals with the incompleteness of medical hospital records based on the literature contained in the review. Results: according to 8 journals explain that the application of incompleteness of medical records from research shows that incomplete remains high at $100 \%$ indicating an occurrence of incompleteness is still frequent and incompatible with the standard for a medical record file. Conclusion: install a minimum evaluation monitoring once a week, creating a file monitoring team to monitor medical records at the hospital.
\end{abstract}

Keywords: of incompleteness medical records, inpatient treatment, step up completeness

\section{PENDAHULUAN}

Berdasarkan Undang-Undang Republik Indonesia No 44 Tahun 2009 tentang rumah sakit pasal 1 ayat 1 menyebutkan bahwa, rumah sakit adalah institusi pelayanan kesehatan yang menyelenggarakan pelayanan kesehatan perseorangan secara paripurna yang menyediakan pelayanan rawat inap, rawat jalan, dan gawat darurat. Setiap pelayanan kesehatan diwajibkan menyelenggarakan rekam medis. Rekam medis adalah berkas yang berisi catatan dan dokumen tentang identitas pasien, pemeriksaan, pengobatan, tindakan dan pelayanan lain yang telah diberikan kepada pasien (Permenkes RI 
No.269/MENKES/PER/III/2008 tentang Rekam Medis). Upaya untuk meningkatkan mutu pelayanan kesehatan yaitu dengan meningkatkan mutu pelayanan rekam medis meliputi kelengkapan, kecepatan dan ketepatan dalam memberikan informasi untuk kebutuhan pelayanan kesehatan. Standar kelengkapan berkas rekam medis harus mencapai angka 100 $\%$ selama $1 \times 24$ jam setelah pasien keluar dari rumah sakit (Kepmenkes RI No.129/MENKES/SK/III/2008 tentang Standart Pelayanan Minimal Rumah Sakit). Ketidaklengkapan pengisian berkas rekam medis rawat inap disebabkan oleh beberapa faktor yaitu faktor man, faktor method, faktor material, faktor machines dan faktor motivation. Faktor man ketidaklengkapan berkas rekam medis ada pada tingkat kesadaran dokter dalam pengisian kelengkapan, faktor method ketidaklengkapan ada pada tingkat monitoring berkas rekam medis, faktor material ketidaklengkapan ada pada rekapitulasi ketidaklengkapan pengisian berkas rekam medis, faktor machine ada pada lembar chekhlist penilaian kelengkapan, dan faktor motivation ada pada pendorong semangat berkerja (Swari,et al, 2019).

Analisis ketidaklengkapan pengisian rekam medis sangat diperlukan, guna mengetahui seberapa besar angka ketidaklengkapan pengisian catatan medis (AKLPCM) di RSU Mitra Medika pada tahun 2018. Ditemukan bahwa dari seluruh berkas rekam medis pasien pulang dari rumah sakit terdapat 13.279 berkas terdapat ketidaklengkapan pengisian sebanyak 7,66\% (1.017) berkas. Salah satu diantaranya adalah ketidaklengkapan pengisian resume medis, ketidaklengkapan pengisian identitas pasien sebanyak 5 formulir $(16,6 \%)$, anamnese 4 $(13,3 \%)$, pemeriksaan fisik $2(6,6 \%)$, diagnosa 1 $(6,6 \%)$, pemeriksaan penunjang $4(13,3 \%)$ dan tindakan medis sebanyak 2 formulir $(6,6 \%)$ (Kartini dan Liddini, 2019). Ketidaklengkapan lembar berdampak kepada menurun kualitas mutu rekam medis sehingga bisa berpengaruh pada proses penilaian akreditasi rumah sakit, selain itu juga berdampak pada jaminan kepastian hukum bagi pasien, tenaga rekam medis, tenaga medis, maupun rumah sakit (Oktavia,et al, 2020).
Berdasarkan permasalahan di atas, maka peneliti membuat kajian literatur review dengan judul ketidaklengkapan berkas rekam medis dengan tujuan (1) Mengidentifikasi ketidaklengkapan pengisian rekam medis, (2) Mengetahui faktor yang mempengaruhi ketidaklengkapan rekam medis, (3) Mengetahui langkah untuk meningkatkan kelengkapan rekam medis. Dalam masalah ini diperlukan sosialisasi atau pemahaman tentang pengisian kelengkapan terkait khusus perawat, petugas rekam medis dan dokter yang menangani pasien

\section{METODE PENELITIAN}

Penelitian ini menggunakan narrative review untuk mengumpulkan, mengetahui dan mengevaluasi analisis ketidaklengkapan berkas rekam medis sesuai dengan standar pelaksanaan kelengkapan berkas rekam medis. Sumber data penelitian ini adalah data primer berupa literature artikel atau jurnal yang relevan dengan analisis kuantitatif rekam medis. Pencarian literature tersebut menggunakan data base Google Scholar. Keyword yang digunakan dalam penelitian ini adalah "Ketidaklengkapan rekam medis" OR "Incompled Medical Record " AND "Rawat Inap", sedangkan kriteria inklusi yang di gunakan yaitu indikator yang digunakan ketidaklengkapan, faktor, analisis. Jurnal yang dipubilkasikan 2016-2020. Bahasa yang digunakan bahasa indonesia dan bahasa inggris. Rancangan penelitian kualitatif dan kuantitatif rekam medis rawat inap rumah sakit.

Kegiatan meringkas informasi penting yang ditemukan pada setiap artikel penelitian yang ditinjau. Informasi ini digunakan untuk menjawab pertanyaan penelitian. Ektraksi data disajikan dalam bentuk tabel di bab hasil.

Sintensis adalah menggabungkan beberapa hasil penelitian dan menarik kesimpulan. Sintensis dalam penelitian ini dilakukan menurut tematema yang ditemukan dari hasil tinjauan. Adapun tema-tema tersebut adalah :

1) Identifikasi pengisian ketidaklengkapan rekam medis

2) Faktor peningkatan mutu rekam medis

3) Langkah untuk mengatasi terjadi ketidaklengkapan pengisian berkas rekam medis. 


\section{HASIL DAN PEMBAHASAN}

\section{HASIL}

Hasil Ekstarsi Data

Tabel 1. Hasil Ekstrasi

\begin{tabular}{|c|c|c|}
\hline $\begin{array}{c}\text { Author (nama dan } \\
\text { tahun) }\end{array}$ & Judul & Hasil \\
\hline Nurhaidah, et al, 2016 & $\begin{array}{l}\text { Faktor-Faktor Penyebab } \\
\text { Ketidaklengkapan Pengisian Rekam } \\
\text { Medis Rawat Inap Di Rumah Sakit } \\
\text { Universitas Muhammadiyah } \\
\text { Malang }\end{array}$ & $\begin{array}{l}\text { Identifikasi ketidaklengkapan pengisian rekam } \\
\text { medis } 100 \%\end{array}$ \\
\hline Maliki, et al, 2018 & $\begin{array}{l}\text { Analisis Ketidaklengkapan } \\
\text { Dokumen Rekam Medis Pada } \\
\text { Kasus Rawat Inap di } \\
\text { RSUD Patut Patuh Patju Gerung }\end{array}$ & $\begin{array}{l}\text { Identifikasi ketidaklengkapan pengisian rekam } \\
\text { medis } \\
\text { - Pengisian identitas ketidaklengkapan } 15,7 \% \\
\text { - Pengisian data klinis ketidaklengkapan } 6,9 . \% \\
\text { - Hasil penunjang } \\
\text { ketidaklengkapan } 8,5 \%\end{array}$ \\
\hline $\begin{array}{l}\text { Hasibuan dan Malau, } \\
2019\end{array}$ & $\begin{array}{l}\text { Ketidaklengkapan Dokumen } \\
\text { Rekam Medis Rawat Inap Pada } \\
\text { Pasien Diabetes Mellitus di RSU } \\
\text { IMELDA Medan }\end{array}$ & $\begin{array}{l}\text { Identifikasi ketidaklengkapan pengisian rekam } \\
\text { medis } \\
\text { - Catatan terintergrasi ketidaklengkapan } 17,40 \% \text {. } \\
\text { - Pengkajian awal ketidaklengkapan } 15,22 \% \text {. } \\
\text { Resume medis ketidaklengkapan } 9.79 \% \text {. } \\
\text { - Informend consent ketidaklengkapan } 17.40 \% \\
\text { - Nama dokter } \\
\text { - ketidaklengkapan } 21,74 \% \\
\text { Tanda tangan dokter ketidaklengkapan } 8.70 \%\end{array}$ \\
\hline $\begin{array}{l}\text { Meyyulinar Helena, } \\
2019\end{array}$ & $\begin{array}{l}\text { Analisi Faktor-Faktor Penyebab } \\
\text { Ketidaklengkapan Informed } \\
\text { Consent Pada Kasus Bedah Di } \\
\text { Rumah Sakit Al Marinir Ciladak }\end{array}$ & Faktor ketidaklengkapan rekam medis \\
\hline Lubis Fitriyani, 2016 & $\begin{array}{l}\text { Tinjauan Ketidaklengkapan } \\
\text { Penulisan Resume Medis Rawat } \\
\text { Inap Di Rumah Sakit Umum } \\
\text { IMELDA Pekerja Indonesia (IPI) } \\
\text { Medan Tahun } 2016\end{array}$ & $\begin{array}{l}\text { Identifikasi ketidaklengkapan pengisian rekam } \\
\text { medis } \\
\text { - Identitas pasien ketidaklengkapan } 12 \% \\
\text { - Nomor rekam medis ketidaklengkapan } 14 \% \text {. } \\
\text { - Anamnesa ketidaklengkapan 34\%. } \\
\text { - Diagnosa ketidaklengkapan } 48 \% \text {. } \\
\text { - Tanda tangan dokter ketidaklengkapan } 30 \% \text {. }\end{array}$ \\
\hline $\begin{array}{l}\text { Esraida dan Napitupulu, } \\
2018\end{array}$ & $\begin{array}{l}\text { Analisis Ketidaklengkapan } \\
\text { Dokumen Rekam Medis Menurut } \\
\text { Standart Akreditasi Rumah Sakit } \\
\text { MKI 19.1 Versi KARS 2012 Di } \\
\text { Rumah Sakit Umum IMELDA } \\
\text { Perkerja Indonesia (RSU IPI) } \\
\text { Medan Tahun } 2018\end{array}$ & $\begin{array}{l}\text { Identifikasi ketidaklengkapan pengisian rekam } \\
\text { medis } \\
\text { - Identitas pasien ketidaklengkapan } 69,14 \% \text {. } \\
\text { - Dokumen pemeriksaan ketidaklengkapan } \\
\text { 33,33\%. } \\
\text { - Diagnosa pendukung ketidaklengkapan } \\
\text { 67,90\%. } \\
\text { - Hasil pengobatan ketidaklengkapan } 46,92 \% \text {. } \\
\text { Justifikasi pengobatan ketidaklengkapan } 62,96 \% \text {. }\end{array}$ \\
\hline Paulus, et al, 2018 & $\begin{array}{l}\text { Faktor-Faktor Yang Berhubungan } \\
\text { Dengan Kelengkapan Dokumen } \\
\text { Rekam Medis Rawat Inap Di } \\
\text { Rumah Sakit Tahun } 2018\end{array}$ & $\begin{array}{l}\text { Langkah meningkatkan kelengkapan rekam medis } \\
: \\
\text { Reward kelengkapan pengisian rekam medis }\end{array}$ \\
\hline Farista, et al, 2020 & $\begin{array}{l}\text { Hubungan Motivasi Dan Supervisi } \\
\text { Terhadap Kelengkapan Pengisian } \\
\text { Resume Medis Oleh Dokter }\end{array}$ & $\begin{array}{l}\text { Langkah meningkatkan kelengkapan rekam medis } \\
: \\
\text { Pemberian Motivasi }\end{array}$ \\
\hline
\end{tabular}

p-ISSN: |e-ISSN: 2807-2596

website: ijhim.stikesmhk.ac.id/index.php/ 


\section{PEMBAHASAN}

\section{Identifikasi Ketidaklengkapan Pengisian Rekam Medis}

Pengisian ketidaklengkapan rekam medis dari hasil penelitian menunjukan bahwa tidak lengkap pada angka $100 \%$.. Ketidaklengkapan pengisian masih rendah pada penelitian menunjukan angka 15,17\%, 6,9\%, 8,5 tidak lengkap. Standar kelengkapan berkas rekam medis harus mencapai $100 \%$ selama 1x24 jam setelah pasien keluar dari rumah sakit. Hasil dari penelitian menunjukan bahwa kelengkapan berkas rekam medis secara keseluruhan masih kurang lengkap karena angka ketidaklengkapan mencapai $100 \%$.

\section{Faktor Yang Mempengaruhi Ketidaklengkapan Rekam Medis}

Berdasarkan data yang di dapat dalam penelitian Meyyulinar Helena, 2019 diketahui bahwa pengaruh ketidaklengkapan rekam medis yaitu terkait dengan :

\section{Perbedaan Persepsi Dokter Tentang Informed Consent}

Pemahaman dokter tentang informed consent masih berbeda-beda, ada 3 (37,5\%) informan menjawab informed consent adalah informasi kepada pasien dan 5 (62,5\%) informan menjawab bahwa informed consent merupakan informasi dan persetujuan tindakan. Hampir semua dokter $(57,1 \%)$ melakukan pengisian persetujuan tindakan (informed consent) di poli klinik dan ada dua dokter yang melakukan di ruang $\mathrm{OK}$ $(28,5 \%)$.Hal ini sejalan dengan penelitian Nurhaidah, et al, 2016 pengisian ketidaklengkapan berkas rekam medis paling tinggi dapat dilihat pada RS Universitas Muhammadiyah Malang, bahwa dari 40 dokumen rekam medis didapatkan bahwa jumlah tidak lengkap adalah $100 \%$, dengan presentasi ketidaklengkapan yang paling banyak adalah dari dokter. Faktor yang menyebabakan ketidaklengkapan pengisian rekam medis adalah tidak adanya kebijakan panduan SOP pengisian rekam medis di RS UMM, hal ini mengakibatkan tidak adanya acuan bagi petugas terkait dalam melakukan pengisian rekam medis sehungga menimbulkan presepsi tentang pengisian kelengkapan. Penelitian Maliki, et al, 2018 pengisian ketidaklengkapan berkas rekam medis paling rendah dapat dilihat pada RSUD Patut Patuh Patju Gerung tahun 2017, bahwa dari 86 dokumen di rawat ini menunjukkan ketidaklengkapan pengisian data identitas yaitu pada $15,17 \%$, ketidaktelitian petugas rekam medis dalam mengisi dan mengecek ulang merupakan salah satu penyebab ketidaklengkapan, pengisian item identifikasi pada formulir persetujuan umum harus diisi secara lengkap karena jika tidak diisi lengkap akibat pada sumber perencanaan rumah sakit dan organisasi pelayanan rumah sakit. Data klinis $6,9 \%$, adanya angka ketidaklengkapan pada formulir tindakan pembedah disebabkan oleh kurang telitinya petugas medis dalam melengkapi formulir persetujuan tindak bedah. Hasil penunjang 8,5\%, ketidaklengkapan pengisian hal ini tentu saja tidak sesuai dengan aturan yang ada, rumah sakit dalam menganalisis rekam medis dilakukan dengan cara meneliti rekam medis yang dihasilkan oleh staf medis dan paramedic serta hasil pemeriksaan penunjang sehingga kebenaran penempatan diagnosa dan kelengkapan dapat di pertanggung jawabkan. Angka presentase ketidaklengkapan berkas rekam medis masih dikatakan tinggi mencapai angka $100 \%$, hal ini masih menjadi permasalahan dalam pengisian rekam medis untuk meningkatkan mutu pelayanan kesehatan di rumah sakit.

\section{Keterlambatan Waktu Praktek Dokter}

Penyebab ketidaklengkapan pengisian persetujuan tindakan (informed consent) yaitu ada dua dokter yang mengatakan jam prakteknya terbatas, ada dua dokter $(25 \%)$ yang mengatakan ada di praktek di tempat lain dan waktu terbatas sehingga selesai praktek langsung pulang karena harus praktek di tempat lain, dokter yang lain mengatakan banyak pasien yang sudah menunggu dari pagi $(75 \%)$.

\section{Kesibukan Dokter}

Banyak pasien yang dioperasi dan dilakukan dalam berurutan mengakibatkan dokter tergesa-gesa dan dokter tidak sempat mengisi persetujuan tindakan (informed consent) bahkan ada dokter yang melakukan operasi lima pasien dalam sehari.

Pengisian informend consent dalam kelengkapan rekam medis sangat diperlukan , dokter seharusnya mengisi formulir informend consent setelah selesai melaksanakan tindakan operasi agar dapat mengurangi pengisian ketidaklengkapan.

\section{Ketergantungan Dokter Terhadap Perawat}

Berdasarkan hasil wawancara dengan informan bahwa di RS AL Marinir Cilandak 
ketergantungan dokter masih tinggi karena perawat harus selalu mengingatkan dokter untuk mengisis persetujuan tindakan (informed consent).

Kerjasama antara dokter dengan perawat untuk pengisian kelengkapan informend consent sangat diperlukan, tetapi dokter seharunya paham untuk melakukan pengisian kelengkapan rekam medis agar kelngkapan bisa berjalan dengan baik.

5. Kurangnya Perhatian Dokter Terhadap Pengisian Informed Consent

Menurut dokter DPJP (Dokter

Penanggung Jawab Pasien), dapat diketahui bahwa perhatian dokter dalam mengisi persetujuan tindakan (informed consent) masih kurang, karena dokter lebih mementingkan dalam memberikan pelayanan terhadap pasien dari pada untuk memikirkan kepentingan administratif.

Kebijakan pengisian informend consent sangat diperlukan untuk pemahaman dokter terkait informend consent. Dengan adanya kebijakan pengisian bisa membantu dokter untuk mengetahui tugas dokter dalam pengisian rekam medis.

\section{Langkah Untuk Meningkatkan Kelengkapan Rekam Medis}

Hasil dari Penelitian menunjukan bahwa langkah meningkatkan kelengkapan rekam medis adalah kebijakan, reward kelengkapan dan motivasi. Langkah untuk meningkatkan kelengkapan dengan cara kebijakan dan reward dapat memberikan motivasi dalam pengisian kelengkapan.

1. Kebijakan Organisasi Rumah Sakit Terkait Informend Consent

Rumah sakit AL Marinir Cilandak sudah mempunyai kebijakan, namun dalam pelaksanaanya sebagian dokter informend consent belum sesuai dalam peraturan perundang-undang dan standar pelayanan yang ada.

2. Kebijakan terkait informend consent menjadi pedoman dalam pengisian informend consent yang di buat oleh rumah sakit, agar dokter bisa menjalankan pelayanan kesehatan dengan cara meningkatkan mutu pelayanan Kesehatan Reward Kelengkapan Rekam Medis. Reward merupakan salah satu faktor penting yang mempengaruhi individu berkerja pada suatu organisasi, pemberian insentif dapat menciptakannmotivasi dan meningkatkan produktivitas, namum sering terabaikan atau kurang dimanfaatkan manager. Pemberian reward kepada dokter yang telah mengisi kelengkapan dengan baik dapat memberikan motivasi u tuk meningkatkan tanggung jawab kelengkapan.

3. Pemberian Motivasi

Motivasi merupakan dorongan yang mengakibatkan seseorang anggota oerganisasi mau dan rela untuk menyerahkan kemauan dalam bentuk kemampuan dan keahlian. Dorongan merupakan arahan untuk memenuhi kebutuhan. Pemberian Motivasi untuk petugas dapat membangkitkan semanagat petugas dalam melakukan kelengkapan rekam medis agar kelengakapan berjalan dengan baik.

\section{SIMPULAN}

Ketidaklengkapan berkas rekam medis masih tinggi mencapai $100 \%$. Hal ini masih menjadi permasalahan dalam berkas rekam medis untuk meningkatkan mutu pelayanan kesehatan di rumah sakit. Faktor ketidaklengkapan rekam medis disebabkan oleh perbedaan persepsi dokter tentang pentingnya informend consent, keterbatasan waktu, kesibukan dokter, ketergantungan dokter terhadap perawat, kurangnya perhatian dokter terhadap informend consent. Langkahlangkah yang dilakukan untuk pengisian kelengkapan rekam medis meliputi kebijakan, reward dan motivasi

\section{DAFTAR PUSTAKA}

Buse K,May N,Walt G.(2005).Malking Health Policy Understanding Public Health .Open University Press MrGraw-Hill House.Berkshire England.UK.

Departemen Kesehatan RI.(2006). UndangUndang No.44 Tahun 2009 Tentang Rumah Sakit.Jakarta: Depkes RI

Farista D.H dan Karyus Alia.(2020). Hubungan Motivasi Dan Suplervisi Terhadap Kelengkapan Pengisian Resume Medis Oleh Dokter.Jurnal Ilmiah Permas: STIKES Kendal,10(1): 429-442.

Hasbuan S.A dan Malau G.(2019). Ketidaklengkapan Dokumen Rekam Medis Rawat Inap Pada Pasien Diabetes Mellitus Di RSU IMELDA Medan. 
Jurnal Ilmiah Perekam dan Informasi Kesehatan IMELDA. 4(2): 675-679.

Kartini S.A dan Liddini H.(2019). Tinjauan Ketidaklengkapan Penulisan Resume Medis Rawat Inap Di Rumah Sakit Umum Mitra Medika Tahun 2019. Jurnal Imiah Perekam dan Informasi Kesehatan IMELDA . 4(2): 680-685.

Kepmenkes RI.(2008). Keputusan Mentri Kesehatan Republik Indonesia Nomor.129/Menkes/SK/II/2008 Tentang Standart Pelayanan Minimal Rumah Sakit. Jakarta : Kemenkes RI.

Lubis, $\quad$ Fitriyani.(2016). Tinjauan Ketidaklengkapan Penulisan Resume Medis Rawat Inap Di Rumah Sakit Umum Pekerja Indonesia (IPI) Medan Tahun 2016. Jurnal Ilmiah Perekam Medis dan Informasi Kesehatan. 2(1): 229-234.

Malik A, Saimi, Purnama H. (2018). Analisis Ketidaklengkapan Dokumen Rekam Medis Pada Kasus Rawat Inap di RSUD Patut Patuh Patju Gerung. Jurnal Kesehatan Qomarul Huda. 6(1): 17-23.

Menteri Kesehatan Republik Indonesia.(2008). Permenkes.Nomor 269/MENKES/PER/III/2008. Jakarta: Menkes RI.

Meyyulinar,Helena.(2019). Analisis FaktorFaktor Ketidaklengkapan Informend Consent Pada Kasus Bedah Di Rumah Sakit AL Marinir Cilandak. JurnalManajemen dan Administrasi Rumah Sakit. 3(1): 34-45.

Oktavia

$\mathrm{D}$,

Hardisman,

Erkadius.(2020).Analisis

Ketidaklengkapan Lembar Informed Cosent Pasien Bedah di Rumah Sakit Tk. III dr. Reksodiwiryo Padang. Jurnal Manajemen Informasi Kesehatan Indonesia . 8(1): 15-24.

Paulus A.A, Dharmawan Y, Agushybana F.(2018).Fator-Faktor Yang Berhubungan Dengan Kelengkapan Dokumen Rekam Medis Rawat Inap Di Rumah Sakit Tahun 2018. Jurnal Kesehatan Masyarakat.7(4): 395-403.
Permenkes RI.(2008). Peraturan Mentri Kesehatan Republik Indonesia Nomor.290/MENKES/PER/III/2008

Tentang Persetujuan Tindakan Kedokteran. Jakarta : Permenkes RI.

Ritonga,A.Z.(2015). Pengaruh Kinerja Petugas Rekam Medis Terhadap Ketidaklengkpan Resume Medis di RSU IMELDA Pekerja Indonesia Medan Tahun 2015. Jurnal Ilmiah Perekam Dan Informasi Kesehatan IMELDA. 1(1): 12-20.

Riyantika,Desy.(2018). Analisis Faktor-Faktor Penyebab Ketidaklengkapan Pengisian Lembar Resume Medis Pasien Rawat Inap. Strada Jurnal Ilmiah Kesehatan. 7(1): 69-73.

Tohardi,Ahmad.(2002). Manajemen Sumber Daya Manusia.Bandung: Mandar Maju.

Swari J.A,Alfiansyah G,Wijayanti A.R,Kurniawati D.R.(2019). Analisis Kelengkapan Pengisian Berkas Rekam Medis Pasien Rawat Inap RSUP Dr.Kariadi Semarang. ARTERI Jurnal Ilmu Kesehatan. 1(1): 50-56.

Shofari,B.2002. PSRK 01 Pengelolaan Rekam Medis dan Dokumentasi Rekam Medis: PORMIKI.

Undang-Undang RI. (2004). Praktek Kedokteran. Bandung: Mauma Aulia.

Uno B.H.(2016).Teori Motivasi \& Pengukurannya.Jakarta: $\quad$ PT.Bumi Aksara. 